\title{
A COMPARATIVE STUDY OF MAGNETIC RESONANCE ANGIOGRAPHY \& DIGITAL SUBTRACTION ANGIOGRAPHY IN DIAGNOSIS OF CEREBRAL ARTERIOVENOUS MALFORMATION
}

\author{
CHOWDHURY AH ${ }^{1}$, ISLAM M ${ }^{2}$, RAHMAN ${ }^{3}$, CHOWDHURY $\mathrm{SJH}^{4}$, ISLAM MN ${ }^{5}$, KHAN $\mathrm{S}^{6}$, RAHMAN $\mathrm{KM}^{7}$, \\ MOHAMMAD QD ${ }^{8}$, SARKER $\mathrm{R}^{9}$ MONDOL $\mathrm{G}^{10}$
}

\begin{abstract}
:
Background and purpose:Although phase-contrast MR angiography (MRA) provides someinformation regarding hemodynamics of cerebral arteriovenous malformations (AVMs), but mostConventional MR angiographic techniques have not been helpful in this respect. We attemptedto determine the value of MR digital subtraction angiography (DSA) in assessing AVMhemodynamics. Soin this retrospective observational study was carried out to compare MRA and DSA in diagnosis of cerebral AVM. Methods and materials: It was a retrospective observational study conducted in the Department of Neurology Dhaka Medical College Hospital (DMCH), Dhaka during the period of January 2010 to December 2010. Thirty patients with haemorrhagic stroke age ranging from 13 to 65 years were selected on the basis of inclusion and exclusion criteria as the study sample. MRA and DSA were done in all the selected patients. Results:The mean age of the patients of haemorrhagic stroke was30.3 \pm 14 .3years and male female ratio was 2.7:1.The venous drainage of AVM 13 and 12 were superficial and deep respectively evaluated 100\% by MRA. In the diagnosis of cerebral AVM nidussize $S_{1}<3, S_{2}: 6 \mathrm{~cm}$ sensitivity $100 \%$ but accuracy $100 \%$ and $73.3 \%$ respectively. Sensitivity $33.3 \%$ found in diagnosis of cerebral $A V M$ nidus size $S_{3}:>6 \mathrm{~cm}, 100 \%$ sensitive in the diagnosis of superficial and deep venous drainage AVM. Regarding the eloquence of brain area 15 was no eloquence by both MRA and DSA and identification of eloquence of brain area sensitivity 73.3\% and accuracy $86.7 \%$.The feeding vessels main vessels was found 22(73.3\%) in both DSA and MRA findings. Distal vessels was seen $8(26.7 \%)$ in DSA but not seen in MRA findings. Intranidal aneurysm and Angiopathic AVM were seen 3(10.0\%) and 4(13.3\%) respectively in DSA, Conclusion: This studywas carried out to diagnose the patients presented with cerebral AVM by MRA and DSA. MRA could not be evaluated flow status of AVM, distal feeding arteries, intranidal aneurysm and angiopathic AVM which could be detected by DSA. So, DSA is superior to MRA in diagnosis of cerebral AVM.
\end{abstract}

Key words:Magnetic resonance angiography, Digital subtraction angiography, Cerebralarteriovenous malformation.

\section{Introduction}

A cerebral arteriovenous malformation (AVM) is an abnormal connection between the arteries and veins in the brain that usually forms before birth. The cause of cerebral arteriovenous malformation is unknown. The condition occurs when arteries in the brain connect directly to nearby veins without having the normal vessels (capillaries) between them ${ }^{1}$. Cerebral AVM occur in about 0.1 percent of the population; one tenth of the incidence of intracranial aneurysms. Supratentorial lesions account for 90 percent of brain AVMs; the remainder are in the posterior fossa ${ }^{2}$. Brain AVMs are considered sporadic congenital developmental vascular lesions. Rare cases of familial

1. Assistant Professor, Department of Neurology, Dhaka Medical College Hospital, Dhaka

2. Registrar, Department of Neurology, National institute of Neurosciences, Dhaka

3. Registrar, Department of Neurology, Sir Salimullah Medical College Mitford Hospital, Dhaka

4. Assistant Professor, Department of Neurology, National institute of Neurosciences, Dhaka

5. Registrar, Department of Neurophysiology, National institute of Neurosciences, Dhaka

6. Associate Professor, Department of Neurology, Dhaka Medical College, Dhaka

7. Assistant Professor, Department of Neurology, Dhaka Medical College, Dhaka

8. PProfessor \& Head, Department of Neurology, Dhaka Medical College, Dhaka.

9. Associate Professor, Department of Radiology, Dhaka Medical College,Dhaka

10. Registrar, Department of Clinical Neurology, National institute of Neurosciences, Dhaka

Bangladesh J Medicine 2013; 24 : 51-58 
brain AVMs have been reported but it is unclear if these are coincidental or indicate true familial occurrence $^{3}$. However, genetic variation may influence brain AVM development and clinical course ${ }^{4}$. Autopsy data suggest that there is an overall frequency of detection of AVMs is $H$ " 4.3 percent of the population $^{5}$. In another autopsy series 46 AVMs were noted among 3200 brain tumour cases, for a frequency of detection in $1.4 \% ; 12.2 \%$ of the cases were symptomatic $^{6}$. More than $50 \%$ of AVMs present with intracranial haemorrhage ${ }^{7}$, although subarachnoid haemorrhage and intraventricularhaemorrhage can occur. The overall frequency of haemorrhage caused by AVM about $H^{\prime \prime} 1 \%$ among all strokes ${ }^{8}$.An overall risk of initial haemorrhage of $\mathrm{H}^{\prime \prime} 2 \%$ to $3 \%$ per year ${ }^{9}$.

Intracranial AVMs may be diagnosed with a variety of diagnostic imaging studies. Computed tomography (CT) of head without contrast has a low sensitivity but calcification and hypo intensity may be noted; enhancement is seen after contrast administration ${ }^{10}$. Magnetic resonance imaging (MRI) is very sensitive. Showing an inhomogeneous signal void on $\mathrm{T}_{1}$ and $\mathrm{T}_{2}$ weighted sequences, commonly with hemosiderin suggesting prior haemorrhage ${ }^{11}$.

Magnetic resonance angiography (MRA) can provide data noninvasively, without detailing factors such as presence of intranidal or feeding artery aneurysms, comprehensive data on venous drainage patterns or subtle AVM nidus characterization ${ }^{12}$. At present the most effective diagnostic tool is intra arterial digital subtraction angiography (DSA) which shows the origin, orientation and course of feeding arteries and draining veins and the location, size and morphology of nidus and eloquence of the adjacent brain region. DSA not only help the proper diagnosis of cerebral AVM but also help in embolization and other treatment procedure. Even DSA can help to detect small size micro AVMs which is not possible to detect by conventional other methods. The current of this study was aimed to evaluate its usefulness in the assessment of hemodynamics of cerebral AVMs and compare between MRA and DSA in diagnosis of cerebral AVM in Bangladesh

\section{Methods and materials:}

It was a retrospective observational study conducted in the Department of Neurology, Dhaka Medical College Hospital (DMCH), Dhaka during the period of January 2010 to December 2010 with the diagnosis of 30 patients of hemorrhagic stroke with inclusion Criteria were follows: (1) Patients with neurological examination and CT scan shows unusual site of hemorrhage (2)CT scan shows worm like irregular appearance suspecting AVM. (3)Patients who were capable to do MRA and DSA and exclusion criteria were1) Ischeamic stroke and (2) Unconscious and non-cooperative patients

Then the selected patients were referred to the Department of Radiology and Imaging, $\mathrm{DMCH}$, for
MRA. Data were recorded in case record form of the patients and same patients were then selected for Intra-arterial DSA. Angiography was performed as intra-arterial (IA) DSA via a femoral arterial approach by two interventional neurologist blinded of MRA findings. Morphology of AVMs were assessed and numbers of AVM were also seen. Presence of any intranidal aneurysm was also assessed. Size of the nidus of AVM was also measured and feeding arteries, draining veins and eloquence brain area were assessed by Spletzer Martin score. Flow status of AVM was also assessed by DSA which was used as the gold standard. Evaluation of the feasibility and potentiality of MRA to diagnose cerebral AVM and identify the location of AVM, measure their size and assess their morphology. Flow status of AVM could not be evaluated by 3D TOF MRA but detected by Phase contrast MRA. Phase contrast MRA was not present in DMCH. The findings of MRA and DSA were directly compared to determine the sensitivity, specificity and accuracy of MRA. Each patient was evaluated immediately and 6 hours after DSA for any post-procedural complications. Each patient was advised to attend Neurology outdoor every month for subsequent followup. During both the procedures (MRA and DSA), the investigator was present and maintained equal standard for all the patients.

Statistical analysis was performed using SPSS 16.0 programmed. Data was defined as means ( \pm standard deviation), frequency distribution and percentage. Chi square test and Kendall $W$ coefficients $(\mathrm{K})$ test were used for measures of agreement between two procedures and validity test was performed to find out sensitivity, specificity, and accuracy, positive predictive value (PPV) and negative predictive value $(\mathrm{NPV})$. $\mathrm{P}$ values <0.05 was considered to be statistically significant.

\section{Resultsand observations :}

The mean age of the patients having features of hemorrhagic stoke was $30.3 \pm 14.3$ years with range from 13 to 65 years and most of the patients found in the age group of $£ 20$ years and the sex distribution of the patients and it was found that 22(73.3\%) and $8(26.7 \%)$ were male and female respectively. Male female ratio was almost $2.7: 1$.

Table-I

Age distribution of the patients $(n=30)$

\begin{tabular}{lcc}
\hline Age (in years) & $\begin{array}{c}\text { No. of Patients } \\
(\mathrm{n}=30)\end{array}$ & Percentage \\
\hline$\leq 20$ & 9 & 30.0 \\
$21-30$ & 8 & 26.7 \\
$31-40$ & 5 & 16.7 \\
$41-50$ & 7 & 23.3 \\
$\geq 51$ & 1 & 3.3 \\
Mean \pm SD & 30.3 & \pm 14.3 \\
Range (min-max) & $(13$ & $-65)$ \\
\hline
\end{tabular}


Table-II

Association between MRA and DSA for identification of venous drainage of AVM evaluated by Spetzler-Martin Score

\begin{tabular}{lcccccc}
\hline $\begin{array}{l}\text { Venous drainage of AVM } \\
\text { evaluated by MRA }\end{array}$ & Superficial venous drainage & \multicolumn{2}{c}{ Evaluated by DSA } \\
& $\mathrm{N}$ & $\%$ & $\mathrm{~N}$ & $\%$ & $\mathrm{~N}$ & $\%$ \\
\hline Superficial venous drainage & 13 & $(100)$ & $(0)$ & 12 & $(100)$ & 0 \\
Deep venous drainage & 0 & $(0)$ & 0 & $(0)$ & $(20)$ \\
Both & 0 & 13 & 12 & $(80)$ \\
\hline Total & 13 & & 5 \\
\hline
\end{tabular}

K value- 0.971 ,P value- $0.001^{\mathrm{s}}$

The mean age of the patients having features of haemorrhagic stroke was $30.3 \pm 14.3$ years with range from 13 to 65 years and most of the patients found in the age group of $\leq 20$ years

Regarding the venous drainage of AVM 13 and 12 were superficial and deep respectively, which were evaluated $100.0 \%$ by both MRA and DSA. However, 5 venous drainage of AVM was both superficial and deep by DSA but 4 venous drainage of AVM was both superficial and deep by MRA and rest 1 venous drainage of AVM was deep by MRA.

Table-III

Association between MRA and DSA for identification of nidus size of cerebral AVM evaluated by Spetzler-Martin Score

\begin{tabular}{|c|c|c|c|c|c|c|}
\hline \multirow{3}{*}{$\begin{array}{l}\text { Size of cerebral AVM } \\
\text { evaluated by MRA }\end{array}$} & \multicolumn{6}{|c|}{ Evaluated by DSA } \\
\hline & \multicolumn{2}{|c|}{$\mathrm{S}_{1}:<3 \mathrm{~cm}$} & \multicolumn{2}{|c|}{$\mathrm{S}_{2}: 3-6 \mathrm{~cm}$} & \multicolumn{2}{|c|}{$\mathrm{S}_{3}:>6 \mathrm{~cm}$} \\
\hline & $\mathrm{N}$ & $\%$ & $\mathrm{~N}$ & $\%$ & $\mathrm{~N}$ & $\%$ \\
\hline$\overline{\mathrm{S}_{1}:<3 \mathrm{~cm}}$ & 7 & $(100)$ & 0 & $(0)$ & 0 & (0) \\
\hline $\mathrm{S}_{2}: 3-6 \mathrm{~cm}$ & 0 & (0) & 11 & (100) & 8 & $(66.7)$ \\
\hline $\mathrm{S}_{3}:>6 \mathrm{~cm}$ & 0 & (0) & 0 & $(0)$ & 4 & (33.3) \\
\hline Total & 7 & & 11 & & 12 & \\
\hline
\end{tabular}

$\mathrm{K}$ value- $0.778, \mathrm{P}$ value- $0.001^{\mathrm{s}}$, Kendall $\mathrm{W}$ coefficients $(\mathrm{K})$ of $0.5-0.8$ were considered to indicate good agreement

A total of 30 patients were included in this study. MRA and DSA were performed of all patients. It was observed according by Spetzler-Martin Score. 7 and 11 AVM nidus size were $\mathrm{S}_{1}$ and $\mathrm{S}_{2}$ respectively, which were evaluated $100.0 \%$ by both MRA and DSA. However, 12 AVM nidus size was $\mathrm{S}_{3}$ : $>6$ cm by DSA but only 4 AVMnidus was $\mathrm{S}_{3}$ : $>6 \mathrm{~cm}$ by MRA and rest 8 AVM nidus size was $\mathrm{S}_{2}$ by MRA. Kendall $W$ coefficients (K) was $0.778(\mathrm{p}<0.001)$, which indicate good agreement with DSA.

Table-IV

$D S A$ and MRA findings of the study patients according to Spetzler-Martin Score $(n=30)$

\begin{tabular}{|c|c|c|c|c|c|}
\hline Patient no & MRA & DSA & Patient no & MRA & DSA \\
\hline 1 & $\mathrm{~S}_{2} \mathrm{~V}_{0} \mathrm{E}_{0}$ & $\mathrm{~S}_{2} \mathrm{~V}_{0} \mathrm{E}_{0}$ & $\overline{16}$ & $\mathrm{~S}_{2} \mathrm{~V}_{1} \mathrm{E}_{0}$ & $\mathrm{~S}_{3} \mathrm{~V}_{1} \mathrm{E}_{1}$ \\
\hline 2 & $\mathrm{~S}_{2} \mathrm{~V}_{0} \mathrm{E}_{0}$ & $\mathrm{~S}_{2} \mathrm{~V}_{0} \mathrm{E}_{0}$ & 17 & $\mathrm{~S}_{3} \mathrm{~V}_{0} \mathrm{E}_{0}$ & $\mathrm{~S}_{3} \mathrm{~V}_{0} \mathrm{E}_{0}$ \\
\hline 3 & $\mathrm{~S}_{2} \mathrm{~V}_{0} \mathrm{E}_{1}$ & 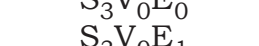 & 18 & $\mathrm{~S}_{3} \mathrm{~V}_{1} \mathrm{E}_{1}$ & $\mathrm{~S}_{3} \mathrm{~V}_{1} \mathrm{E}_{1}$ \\
\hline 4 & $\mathrm{~S}_{1} \mathrm{~V}_{1} \mathrm{E}_{0}$ & 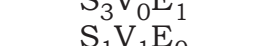 & 19 & $\mathrm{~S}_{2} \mathrm{~V}_{1} \mathrm{E}_{0}$ & $\mathrm{~S}_{2} \mathrm{~V}_{1} \mathrm{E}_{0}$ \\
\hline 5 & $\mathrm{~S}_{1} \mathrm{~V}_{1} \mathrm{E}_{0}$ & $\begin{array}{l}\mathrm{S}_{1} \mathrm{~V}_{1} \mathrm{E}_{0} \\
\mathrm{~S}, \mathrm{~V}, \mathrm{E}_{0}\end{array}$ & 20 & $\mathrm{~S}_{2} \mathrm{~V}_{1} \mathrm{E}_{1}$ & $\mathrm{~S}_{2} \mathrm{~V}_{1} \mathrm{E}_{1}$ \\
\hline 6 & $\mathrm{~S}_{2} \mathrm{~V}_{0} \mathrm{E}_{0}$ & $\begin{array}{l}\mathrm{S}_{1} \mathrm{v}_{1} \mathrm{E}_{0} \\
\mathrm{~S}_{2} \mathrm{~V}_{0} \mathrm{E}_{0}\end{array}$ & 21 & $\mathrm{~S}_{3} \mathrm{~V}_{0} \mathrm{~V}_{1} \mathrm{E}_{1}$ & $\mathrm{~S}_{3} \mathrm{~V}_{0} \mathrm{~V}_{1} \mathrm{E}_{1}$ \\
\hline 7 & $\mathrm{~S}_{2} \mathrm{~V}_{0} \mathrm{E}_{1}$ & $\begin{array}{l}\mathrm{S}_{2} \mathrm{v}_{0} \mathrm{E}_{0} \\
\mathrm{~S}_{2} \mathrm{~V}_{0} \mathrm{E}_{1}\end{array}$ & 22 & $\mathrm{~S}_{3} \mathrm{~V}_{0} \mathrm{~V}_{1} \mathrm{E}_{1}$ & $\mathrm{~S}_{3} \mathrm{~V}_{0} \mathrm{~V}_{1} \mathrm{E}_{1}$ \\
\hline 8 & $\mathrm{~S}_{2} \mathrm{~V}_{0} \mathrm{E}_{0}$ & $\mathrm{~S}_{3} \mathrm{~V}_{0} \mathrm{E}_{1}$ & 23 & $\mathrm{~S}_{1} \mathrm{~V}_{1} \mathrm{E}_{1}$ & $\mathrm{~S}_{1} \mathrm{~V}_{1} \mathrm{E}_{1}$ \\
\hline 9 & $\mathrm{~S}_{2} \mathrm{~V}_{0} \mathrm{E}_{0}$ & $\mathrm{~S}_{2} \mathrm{~V}_{0} \mathrm{E}_{0}$ & 24 & $\mathrm{~S}_{1} \mathrm{~V}_{1} \mathrm{E}_{0}$ & $\mathrm{~S}_{1} \mathrm{~V}_{0} \mathrm{~V}_{1} \mathrm{E}_{0}$ \\
\hline 10 & $\mathrm{~S}_{2} \mathrm{~V}_{0} \mathrm{E}_{0}$ & $\mathrm{~S}_{2} \mathrm{~V}_{0} \mathrm{E}_{0}$ & 25 & $\mathrm{~S}_{2} \mathrm{~V}_{0} \mathrm{~V}_{1} \mathrm{E}_{1}$ & $\mathrm{~S}_{2} \mathrm{~V}_{0} \mathrm{~V}_{1} \mathrm{E}_{1}$ \\
\hline 11 & $\mathrm{~S}_{1} \mathrm{~V}_{1} \mathrm{E}_{0}$ & $\mathrm{~S}_{1} \mathrm{~V}_{1} \mathrm{E}_{1}$ & 26 & $\mathrm{~S}_{2} \mathrm{~V}_{1} \mathrm{E}_{1}$ & $\mathrm{~S}_{3} \mathrm{~V}_{1} \mathrm{E}_{1}$ \\
\hline 12 & $\mathrm{~S}_{1} \mathrm{~V}_{1} \mathrm{E}_{0}$ & $\mathrm{~S}_{1} \mathrm{~V}_{1} \mathrm{E}_{0}$ & 27 & $\mathrm{~S}_{1} \mathrm{~V}_{1} \mathrm{E}_{0}$ & $\mathrm{~S}_{1} \mathrm{~V}_{1} \mathrm{E}_{0}$ \\
\hline 13 & $\mathrm{~S}_{2} \mathrm{~V}_{0} \mathrm{E}_{0}, \mathrm{~S}_{1} \mathrm{~V}_{1} \mathrm{E}_{0}$ & $\mathrm{~S}_{2} \mathrm{~V}_{0} \mathrm{E}_{0}, \mathrm{~S}_{1} \mathrm{~V}_{1} \mathrm{E}_{0}$ & 28 & $\mathrm{~S}_{2} \mathrm{~V}_{0} \mathrm{E}_{0}$ & $\mathrm{~S}_{2} \mathrm{~V}_{0} \mathrm{E}_{0}$ \\
\hline 14 & $\mathrm{~S}_{2} \mathrm{~V}_{0} \mathrm{~V}_{1} \mathrm{E}_{0}$ & $\mathrm{~S}_{2} \mathrm{~V}_{0} \mathrm{~V}_{1} \mathrm{E}_{0}$ & 29 & $\mathrm{~S}_{2} \mathrm{~V}_{0} \mathrm{E}_{0}$ & $\mathrm{~S}_{3} \mathrm{~V}_{0} \mathrm{E}_{1}$ \\
\hline 15 & $\mathrm{~S}_{2} \mathrm{~V}_{1} \mathrm{E}_{1}, \mathrm{~S}_{1} \mathrm{~V}_{1} \mathrm{E}_{1}$ & $\mathrm{~S}_{3} \mathrm{~V}_{1} \mathrm{E}_{1}, \mathrm{~S}_{1} \mathrm{~V}_{1} \mathrm{E}_{1}$ & 30 & ${ }_{0} \mathrm{E}_{0}$ & $\mathrm{~S}_{3} \mathrm{~V}_{0} \mathrm{E}_{0}$ \\
\hline
\end{tabular}

${ }^{*} \mathrm{E}=$ eloquence of brain area, $\mathrm{S}=$ size of cerebral AVM nidus, $\mathrm{V}=$ venous drainage pattern. $\mathrm{S}_{1}:<3 \mathrm{~cm} \quad \mathrm{~S}_{2}: 3-6 \mathrm{~cm} \quad \mathrm{~S}_{3}:>6 \mathrm{~cm}$ $\mathrm{V}_{0}$ : Superficial venous drainage $\mathrm{V}_{1}$ : Deep venous drainage $\mathrm{E}_{0}$ : No eloquence of brain area $\mathrm{E}_{1}$ : Eloquence of brain area According to Spetzler-Martin Score MRA and DSA findings are depicted in the above table. 
Table-V

Comparison between MRA and DSA for identification size $\left(S_{1}:<3 \mathrm{~cm}\right)$ of cerebral AVM nidus size.

\begin{tabular}{lccc}
\hline MRA & DSA & Negative for $\mathrm{S}_{1}:<3 \mathrm{~cm}$ & Total \\
\hline Positive for $\mathrm{S}_{1}:<3 \mathrm{~cm}$ & 7 & 0 & 7 \\
Negative for $\mathrm{S}_{1}:<3 \mathrm{~cm}$ & 0 & 23 & 23 \\
Total & 7 & 23 & 30 \\
\hline
\end{tabular}

Sensitivity 100\%, Specificity 100\%, Accuracy 100\%, Positive predictive value 100\%, Negative predictive value $100 \%$.

Table-VI

Comparison between MRA and DSA for identification size $\left(S_{2}: 3-6 \mathrm{~cm}\right)$ of cerebral AVM nidus size.

\begin{tabular}{|c|c|c|c|}
\hline \multirow[t]{2}{*}{ MRA } & \multicolumn{3}{|c|}{ DSA } \\
\hline & Positive fors $\mathrm{S}_{2}: 3-6 \mathrm{~cm}$ & Negative for $\mathrm{S}_{2}: 3-6 \mathrm{~cm}$ & Total \\
\hline Positive for $\mathrm{S}_{2}: 3-6 \mathrm{~cm}$ & 11 & 8 & 19 \\
\hline$\underline{\text { Negative for } \mathrm{S}_{2}: 3-6 \mathrm{~cm}}$ & 0 & 11 & 11 \\
\hline Total & 11 & 19 & 30 \\
\hline
\end{tabular}

Sensitivity $100 \%$, Specificity $57.9 \%$, Accuracy $73.3 \%$, Positive predictive value $57.9 \%$, Negative predictive value $100 \%$.

Table-VII

Comparison between MRA and DSA for identification size $\left(S_{3}:>6 \mathrm{~cm}\right)$ of cerebral AVM nidus size.

\begin{tabular}{lccc}
\hline MRA & Positive for $\mathrm{S}_{3}:>6 \mathrm{~cm}$ & Negative for $\mathrm{S}_{3}:>6 \mathrm{~cm}$ & Total \\
\hline Positive for $\mathrm{S}_{3}:>6 \mathrm{~cm}$ & 4 & 0 & 4 \\
Negative for $\mathrm{S}_{3}:>6 \mathrm{~cm}$ & 8 & 18 & 26 \\
\hline Total & 12 & 18 & 30 \\
\hline
\end{tabular}

Sensitivity 33.3\%, Specificity 100\%, Accuracy 73.3\%, Positive predictive value 100\%, Negative predictive value $69.2 \%$.

Table-VIII

Comparison between MRA and DSA for identification of both (superficial and deep venous drainage).

\begin{tabular}{lccc}
\hline MRA & \multicolumn{2}{c}{ DSA } \\
& $\begin{array}{c}\text { Positve for both } \\
\text { (superficial \&deep } \\
\text { venous drainage) }\end{array}$ & $\begin{array}{c}\text { Negative for both } \\
\text { (superficial \& deep } \\
\text { venous drainage) }\end{array}$ \\
\hline Positive for both (superficial \&deep venous drainage) & 4 & 0 \\
Negative for both (superficial \&deep venous drainage) & 1 & 25 & 26 \\
\hline Total & 5 & 25 & 30 \\
\hline
\end{tabular}

Sensitivity 80.0\%, Specificity 100\%, Accuracy 96.7\%, Positive predictive value 100\%, Negative predictive value $96.2 \%$.

Table-IX

Comparison between MRA and DSA for identification of Eloquence of brain area evaluated by Spetzler-Martin Score.

\begin{tabular}{|c|c|c|c|c|c|}
\hline \multirow[t]{3}{*}{$\overline{\mathrm{MRA}}$} & \multicolumn{4}{|c|}{ DSA } & \multirow[b]{3}{*}{ Total } \\
\hline & \multicolumn{2}{|c|}{$\begin{array}{c}\text { Positive for eloquence of } \\
\text { brain area }\end{array}$} & \multicolumn{2}{|c|}{$\begin{array}{l}\text { Negative for eloquence } \\
\text { of brain area }\end{array}$} & \\
\hline & $\mathrm{N}$ & $\%$ & $\mathrm{~N}$ & $\%$ & \\
\hline Positive for eloquence ofbrain area & 11 & 73.3 & 0 & 11 & \\
\hline Negative for eloquence of brain area & 44 & 26.7 & 15 & 100 & 19 \\
\hline Total & 15 & 15 & 30 & & \\
\hline
\end{tabular}

$\mathrm{K}$ value-0.761.P value-0.001 ${ }^{\mathrm{s}}$

Regarding the eloquence of brain area 15 was no eloquence by both MRA and DSA. However, 15 eloquence of brain area was eloquence detected by DSA but 4 eloquence of brain area not detected by MRA.

Sensitivity 73.3\%, Specificity 100\%, Accuracy 86.7\%, Positive predictive value 100\%, Negative predictive value $78.9 \%$. 
Table-X

Association between MRA and DSA findings for identification size of cerebral AVM nidusvenous drainage pattern and eloquence of brain area evaluated by Spetzler-Martin Score

\begin{tabular}{lcc}
\hline MRA findings of AVM & No of patients & Percentage \\
\hline All match with DSA & 16 & 53.3 \\
Any one mismatch with DSA & 11 & 36.7 \\
Two mismatch with DSA & 3 & 10.0 \\
\hline
\end{tabular}

K value- 0.743 , P value- $0.001^{\mathrm{s}}$

It was observed that MRA findings of AVM compared with DSA finding 16(53.3\%) was all matched, 11(36.7\%) any one mismatch (S or V or E) with DSA and $3(10.0 \%)$ two mismatch (S with V, S with E and V with E) DSA.

Table-XI

$D S A$ and MRA findings of the study patients $(n=30)$

\begin{tabular}{lccccc}
\hline & \multicolumn{2}{c}{ DSA (n=30) } & \multicolumn{2}{c}{ MRA (n=30) } & P \\
& $\mathrm{n}$ & $\%$ & $\mathrm{~N}$ & $\%$ & Value \\
\hline Blood flow in AVM & 30 & 100 & 0 & 0 & $0.001^{\mathrm{s}}$ \\
Feeding vessels & & & & & \\
$\quad$ Main vessels & 22 & 73.3 & 22 & 73.3 & $1.000^{\mathrm{ns}}$ \\
$\quad$ Distal vessels & 8 & 26.7 & 0 & 0 & $0.002^{\mathrm{s}}$ \\
Intranidal aneurysm & 3 & 10.0 & 0 & 0 & $0.075^{\mathrm{ns}}$ \\
Angiopathic AVM & 4 & 13.3 & 0 & 0 & $0.038^{\mathrm{s}}$ \\
\hline
\end{tabular}

$\mathrm{S}=$ SignificantNS= Not Significant. $\mathrm{P}$ value reached from Chi square test.

Blood flow in AVM was found in all patients in DSA but none was found in MRA findings. Regarding the feeding vessels main vessels was found $22(73.3 \%)$ in both DSA and MRA findings. Distal vessels was seen $8(26.7 \%)$ in DSA but not seen in MRA findings. Intranidal aneurysm and Angiopathic AVM were seen $3(10.0 \%)$ and $4(13.3 \%)$ respectively in DSA, which were not seen by MRA findings.

\section{Discussion:}

This retrospective observational study was carried out to compare MRA and DSA in nidus size, venous drainage, eloquence of the adjacent brain region, feeding arteries, draining veins, location and flow status of cerebral AVMs.

In this present study it was observed that the mean age of the patients having features of haemorrhagicstoke from AVM was $30.3 \pm 14.3$ years with range from 13 to 65 years and most of the patients found in the age group of £20 years(Table I). Nagarajaet al. (2005) observed the mean age was 38 years, which is comparable with the current study. ${ }^{13}$ Hadizadehet al. (2001) done a prospective intra individual comparative study and found the mean age was $41.9 \pm 14.0$ years with range from 23 to 69 years, which is higher with the present study ${ }^{14}$. Because life expectancy more and geographical distribution.

Regarding the venous drainage of AVM it was observed in this current study that 13 and 12 were superficial and deep respectively, which were evaluated $100 \%$ by both MRA and DSA. However, 5 venous drainage of AVM was both superficial and deep by DSA but 4 venous drainage of AVM was both superficial and deep by MRA and rest 1 venous drainage of AVM was deep by MRA which indicate good agreement with DSA performed by Kendall $W$ coefficients $(\mathrm{K})$ was 0.971 ( $p<0.001)$.(TableII) Hadizadehet al. (2001) found that deep venous was present in five of 18 patients, where as in 13 of 18 patients only superficial veins were involved in the drainage of the cerebral AVM ${ }^{15}$. Duran et al. (2002) mentioned that the vessel to background contrast and contrast-to-noise was significantly $(p<0.001)$ better for the CE-MRA for all vascular components $^{16}$. CE MRA was able to clearly detect and delineate the venous drainage patterns in correlation with the digital subtraction angiography. The TOF MRA could demonstrate the exact venous drainage in only 9 patients. No statistical difference between CE MRA and DSA ( $>>0.05)$. Contrast- 
enhanced MRA was significantly better than TOF MRA $(\mathrm{p}<0.05)$.

In this study it was observed according by SpetzlerMartin Score, 7 and 11 AVM nidus size were $\mathrm{S}_{1}$ and $\mathrm{S}_{2}$ respectively, which were evaluated $100.0 \%$ by both MRA and DSA(Table III \&IV). However, 12 AVM nidus size was $\mathrm{S}_{3}:>6 \mathrm{~cm}$ by DSA but only 4 AVM nidus was $\mathrm{S}_{3}$ : $>6 \mathrm{~cm}$ by MRA and rest 8 AVM nidus size was $\mathrm{S}_{2}$ by MRA. Kendall $W$ coefficients $(\mathrm{K})$ was 0.778 $(\mathrm{p}<0.001)$ which indicate good agreement with DSA for identification of size of cerebral AVM evaluated by MRA. Hadizadeh et al. (2001) found that intra observer agreement of nidus size measurement was excellent $(\mathrm{K}=0.955, \mathrm{P}<0.013) .{ }^{14}$

Hadizadehet al. (2001) mentioned in their study that Splitzer-Martin classification of cerebral AVM with 4D contrasted enhanced MR angiography and those with DSA were as follows: grade I, four patients; grade II, eleven patients; grade III two patients, grade IV one patient. Classification matched in 18 of 18 (100\%) patients for both observer which yielded 100\% intraobserver agreement $(K=1) .{ }^{14}$

In this current study it was found in MRA for evaluation of size $\left(\mathrm{S}_{1}:<3 \mathrm{~cm}\right)$ of cerebral AVM nidus size true positive 7 and no false positive, no false negative and true negative 23 cases. In the diagnosis of cerebralAVM nidus size $\mathrm{S}_{1}:<3 \mathrm{~cm}$, sensitivity $100 \%$, specificity $100 \%$, accuracy $100.0 \%$, positive predictive values $100 \%$ and negative predictive values $100 \%$ of the MRA.(TableV)

In MRA for evaluation of size $\left(\mathrm{S}_{2}: 3-6 \mathrm{~cm}\right)$ of cerebral AVM nidus size, true positive 11 and false positive 8 , no false negative and true negative 11 cases. In diagnosis of cerebral AVM nidus size $\mathrm{S}_{2}: 3-6 \mathrm{~cm}$ sensitivity $100 \%$, specificity $57.9 \%$, accuracy $73.3 \%$, positive predictive values $57.9 \%$ and negative predictive values $100 \%$ of the MRA.(TableVI)

In MRA for evaluation of size $\left(\mathrm{S}_{3}:>6 \mathrm{~cm}\right)$ of cerebral AVM nidus size, true positive 4 and no false positive, false negative 8 and true negative 18 cases. In diagnosis of cerebral AVM nidus size $\mathrm{S}_{3}:>6 \mathrm{~cm}$ sensitivity $33.3 \%$, specificity $100 \%$, accuracy $73.3 \%$, positive predictive values $100 \%$ and negative predictive values $69.2 \%$ of the MRA(TableVII).

In accordance with the Spetzler-Martin classification, AVMs were awarded scores depending on their nidal size (Spetzler and Martin 1986) ${ }^{16}$. Warren et al. (2001) reported that CCA demonstrated 27 AVMs with maximal linear dimensions of less than $3 \mathrm{~cm}$ (one point) and 14 AVMs with maximal linear dimensions of 3 to $6 \mathrm{~cm}$ (two points). The authors further stated that MR DSA demonstrated a maximal linear dimension correlation of $0.93 .^{17}$ All techniques exhibited better correlations for size determinations for smaller $(<3-\mathrm{cm})$ AVMs than for larger $(3-6 \mathrm{~cm})$ AVMs. CE SLINKY MR angiography demonstrated the best inter modality correlation for both small and medium-sized AVMs. Routine SLINKY MR angiography exhibited correlation coefficients of 0.87 for AVMs less than $3 \mathrm{~cm}$ in size and 0.78 for AVMs 3 to $6 \mathrm{~cm}$ in size, whereas MR DSA exhibited coefficients of 0.82 for AVMs less than $3 \mathrm{~cm}$ in size and 0.79 for AVMs 3 to $6 \mathrm{~cm}$ in size. Nagarajaet al. (2005) found in their study that the AVM nidus was well demonstrated by MR-DSA and SLINKY MRA in all 60 cases $^{13}$. The latter divides the AVMs into $0 \mathrm{~cm}-3 \mathrm{~cm}$ and $3 \mathrm{~cm}-6 \mathrm{~cm}$ groups in accordance with the Spetzler-Martin grading system. The AVM volume data are presented in a similar fashion. Hadizadehet al. (2001) observed that the mean $( \pm \mathrm{SD})$ size of cerebral AVM at 4D contrasted enhanced MR angiography was $2.5 \pm 1.2 \mathrm{~cm}$ with ranged from $0.5-5.3 \mathrm{~cm}^{14}$. Duran et al. (2002) found that contrast-enhanced MRA was able to detect all AVMs, whereas the TOF MRA failed in 1 patient with a very small AVM 15.

In MRA for evaluation of both (superficial and deep venous drainage), true positive 4 and no false positive, false negative 1 and true negative 25 cases. In diagnosis of superficial venous drainage and deep venous drainage sensitivity $80.0 \%$, specificity $100 \%$, accuracy $96.7 \%$, positive predictive values $100 \%$ and negative predictive values $96.2 \%$ of the MRA (TableVIII)

In MRA for evaluation of eloquence of brain area, true positive 11 and no false positive, false negative 4 and true negative 15 cases. In the diagnosis of identification of Eloquence of brain area, sensitivity $73.3 \%$, specificity $100 \%$, accuracy $86.7 \%$, positive predictive values $100 \%$ and negative predictive values $78.9 \%$ of the MRA(Table IX). Mori et al. (2002) found in their study that the 2D MRDSA and T2-weighted image evaluation, and a comparison of the two are shown in Tables I, II and III. The sensitivity, specificity, positive and negative predictive values of 2D MRDSA was 87, 100, 100 and $78 \%$, respectively. Using nidus flow void on T2-weighted images, the sensitivity, specificity, positive and negative predictive values were $80,91,96$ and $66 \%$, respectively ${ }^{18}$. Nidus flow void was equivocal or absent on T2-weighted images in four of 78 cases; however, early venous filling was clearly seen on 2D MRDSA. Mori et al. (2003) observed the sensitivity, specificity, positive and negative predictive values of 2D MRDSA were $87,100,100$ and $78 \%$, respectively. Using nidus flow void on T2-weighted images, the sensitivity, specificity, positive and negative predictive values 
were $80,91,96$ and $66 \%$, respectively ${ }^{18}$. The above findings are consistent with the current study.

Rose et al. (2005) found by $k$ analysis agreement was highest for venous drainage pattern $(k=0.90)$, intermediate for eloquence $(k=0.71)$, and lowest for size $(k=0.67)$, with substantial agreement on overall grade $(k=0.61)^{19}$. It was observed in this current study that MRA findings of AVM compared with DSA finding more than a half $(53.3 \%)$ was all matched, $36.7 \%$ any one mismatch ( $\mathrm{S}$ or $\mathrm{V}$ or $\mathrm{E}$ ) with DSA and $10.0 \%$ two mismatch ( $\mathrm{S}$ with $\mathrm{V}, \mathrm{S}$ with $\mathrm{E}$ and $\mathrm{V}$ with $\mathrm{E}$ ) DSA, which indicate good agreement with DSA with Kendall $W$ coefficients $(k=0.743 \mathrm{p}<0.001)$.(Table X)

In the present study blood flow in AVM was found in all patients in DSA but none was found in MRA.(TableXI) Regarding the feeding vessels main vessels was found $73.3 \%$ in both DSA and MRA findings. Distal vessels were seen $26.7 \%$ in DSA but not seen in MRA. Intranidal aneurysm and Angiopathic AVM were seen $10.0 \%$ and $13.3 \%$ respectively in DSA, which were not seen by MRA findings. Duran et al. (2002) found the number of detected feeding arteries, 32 by TOF MRA, 33 by CE MRA and 36 by DSA ${ }^{15}$. No statistical difference between CE MRA and TOF MRA ( $p>0.05$ ). Nidus flow void was equivocal or absent on T2-weighted images in four of 78 cases; however, early venous filling was clearly seen on 2D MRDSA. The authors encountered several cases in which residual AVMs were clearly recognized as early venous filling on 2D MRDSA although nidus flow void was equivocal or absent on T2-weighted images. In the assessment of the different angio architectural components both MRA techniques were able to detect all feeding arteries present on the conventional angiograms. A total of 55 patent AVMs, mean ratings of nidus flow voids, feeding vessels, nidi, draining vessels and early venous filling on MRI were $2.8(k=0.68), 2.4(0.69)$, $2.6(0.89), 2.8(0.80)$ and $2.8(0.76)$, respectively. Warren et al. (2001) have done a study on 88 arterial feeding vessels to the $41 \mathrm{AVMs}$, as determined using CCA. Complete agreement was observed in 71 of 88 cases $(80.7 \%)$ using CE SLINKY MR angiography. ${ }^{17}$ Fifteen vessels observed with CCA were not identified, two vessels were misidentified, and two vessels were incorrectly identified because they were not observed using CCA. MR DSA demonstrated good agreement with CCA results, correctly identifying $81.8 \%$ of the arterial feeders. MR DSA did not record 12 vessels described by CCA as being nidal feeders, and MR DSA misidentified 4 additional vessels. CCA indicated that five of the patients had aneurysms. Two patients had two or more aneurysms on enlarged feeding arteries. A single intranidal aneurysm demonstrated by CCA was not observed by SLINKY MR angiography. AlShahi and Warlow (2001) found the high flow, low resistance shunt of an AVM may recruit collateral supply form surrounding vascular territories in addition to the main feeding vessels, sometimes called 'angiomatous change. ${ }^{2}$ Aneurysms are also associated with AVMs in $10 \%$ of patients in many series $^{7,2,19}$.

\section{Conclusion:}

MRA could not be evaluated flow status of AVM, distal feeding arteries, intranidal aneurysm and angiopathic AVM which could be detected by DSA. So, DSA is superior to MRA in diagnosis of cerebral AVM.

\section{References:}

1. Zivin JA 2008, 'Haemorrhagic cerebrovascular disease. In: Goldman L, Ausiello D, eds, Cecil Medicine $23^{\text {rd }}$ ed. Philadelphia Pa: Saunders Elsevier; 237: Chap 432.

2. Al-Shahi R and Warlow C 2001, 'A systematic review of the frequency and prognosis of arteriovenous malformation of the brain in adults', Brain, vol.124, pp.1900-1926.

3. Beijnum, V, Vander, J, Worp HB, Schippers, HM et al. 2007, 'Familial occurrence of brain arteriovenous malformation; a systemic review', J. NeurolNeurosurg Psychiatry, vol. 78, p. 1213.

4. Hashimoto, T. Lawton, MT, Wen G et al. 2004, 'Gene microarray analysis of human brain arteriovenous malformation', Neurosurgery, vol. 54, p. 410 .

5. Michelson WJ 1978, 'Natural history and patho physiology or arteriovenous malformation', Clinical Neurosurgery, vol.26, pp. 307-313.

6. The Arteriovenous Malformation study group. Arteriovenous malformation of the brain in adults, 1999, $N$ Engl J Med, vol. 340, pp. 1812-1818.

7. Brown RD, Wiebers DO, Forbes G. et al. 1988, 'The natural history of unruptured intracranial arteriovenous malformation', J Neurosurgery, vol. 68, pp.352-357.

8. Furlan AS, Wlishant JP, Elveback LR 1979, 'The decreasing incidence of primary intracerebral; a population study', Ann Neurol, vol. 5, pp. 367-373.

9. Mast H, Mohr JP, Osipov A 1995 "Stea" is an unestablished mechanism for the clinical presentation of cerebral arteriovenous malformation', Stroke, vol. 26, pp. 1215-1220.

10. Kumen AJ, Fox AJ, Vinuela F et al.1984, 'Revisted old and new CT findings in unruptured larger arterio venous malformation of the brain', vol. 8, pp. 648655.

11. Huston J, Rufenacht D A, Ehman RT et al. 1991, 'Intracranial aneurysms and vascular malformation; 
comparision of time of flight and phase-contrast MR angiography', Radiology, vol. 181, pp. 721-730.

12. Brown RD, Wiebers DO, Torner JC et al. 1996, 'Frequency of intracranial haemorrhage as a presenting symptom subtype analysis; a population based study of intracranial vascular malformation in Olmsted country Minnesota', J Neurosurgery, vol. 85, pp. 29-32.

13. Nagaraja SD, Capener SC, Coley KJ, Lee ID, Wilkinson AA, Kemeny PD 2005, 'Brain arteriovenous malformations: measurement of nidal volume using a combination of static and dynamic magnetic resonance angiography techniques', Neuroradiology, vol. 47, pp. 387-392.

14. Hadizadeh DR, Falkenhausen MV, Gieseke J et al. 2008, 'Cerebral Arteriovenous Malformation: SpetzlerMartin Classification at Subsecond- TemporalResolution Fourdimensional MR Angiography', Radiology: vol. 246: p. 1.

15. Duran SO, Schoenberg WT, Yuh MV, Knopp G, Van Kaick M, Essig2002, 'Cerebral arteriovenous malformations: morphologic evaluation by ultrashort
3D gadolinium-enhanced MR angiography', EurRadiol, vol. 12, pp. 2957-2964

16. Spetzler RF, Martin NA 1986, 'A proposed grading system for arteriovenous malformations. J Neurosurg. Vol. 65, pp.476-483,.

17. Warren DJ, Hoggard N, Walton L et al. 2001, ,Cerebral Arteriovenous Malformations: Comparison of NovelMagnetic Resonance Angiographic Techniques and Conventional Catheter Angiography', Neurosurgery, vol. 48, no. 5.

18. Mori HS, Aoki T, Okubo N, Hayashi T, Masumoto T, Yoshikawa M, Tago M et al. 2003, Two-dimensional thick-slice MR digital subtraction angiography in the assessment of small to medium-size intracranial arteriovenous malformations', Neuroradiology, vol. 45:, pp. 27-33.

19. Rose Du, Christopher F. Dowd, S. Clairborne Johnston, William L. Young, Michael T. Lawton 2005, 'Interobserver Variability In Grading Of Brain Arteriovenous Malformations Using The SpetzlerMartin System', Neurosurgery, vol. 57, pp. 668-675. 